1. O conjunto de procedimentos constantes deste artigo foi desenvolvido, e vem sendo exercitado, na disciplina de Qualidade Espacial, oferecida pelo autor no Propar/UFRGS, Curso de Pós-Graduação em Arquitetura da Universidade Federal do Rio Grande do Sul (UFRGS).

2. PhD pela University College London, professor do Departamento de Arquitetura da UFRGS, arquiteto pela UFRGS.

E-mail: douglasaguiar@ufrgs.br.

DOI: 10.5752/P.2316-1752.2015v22n31p96 


\title{
O PAPEL DA CAMINHADA NA ARQUITETURA'
}

\author{
THE ROLE OF WALKING IN ARCHITECTURE
}

EL PAPEL DE LA CAMINADA EN LA ARQUITECTURA

Douglas Aguiar ${ }^{2}$

\section{Resumo}

O artigo consta de uma exploração teórica, metodológica e empírica sobre a utilização da caminhada como método de estudo e pesquisa em Arquitetura, considerando sua relevância no atual momento da disciplina. Elabora-se um método, o método do observador, com o objetivo de avaliar a qualidade de situações espaciais com base naquilo que é visto e sentido por quem percorre aquela situação, aquela arquitetura, tanto na escala do edifício quanto na escala da cidade. O artigo apresenta, na primeira parte, uma revisão de literatura dos principais autores contribuintes no tópico. Na segunda parte, apresenta o conjunto de procedimentos constituintes do método propriamente dito. Na terceira parte, apresenta um estudo de caso em que o método do observador é exercitado.

Palavras-chave: Caminhada. Passeio arquitetônico. Qualidade especial. Funcionalidade. Legibilidade.

\begin{abstract}
The article presents an exploration - theoretical, methodological and empirical - about the utilization of the walk as a method of study and research in architecture. With this aim it is elaborated a method, the method of the observer, for assessing the quality of spatial situations from the standpoint of what is seen and what is felt by the ones who walk through those same situations, both at the building and at the urban scale. The article presents in its first part a literature review of the authors regarded as main contributors to the topic. In the second part the article presents the set of proceedings that constitute the method itself. In a third part the article presents a case study where the method of the observer is practised.
\end{abstract}

Keywords: The walk. Architectural promenade. Spatial quality. Functionality. Legibility.

\section{Resumen}

El artículo consta de una exploración - teórica, metodológica y empírica - sobre la utilización de la caminada como método de estudio en arquitectura. Elabora-se con ese objetivo un método, el método del observador, de evaluar la calidad de situaciones espaciales a partir de lo que es visto y sentido por quien recorre aquella situación, aquella arquitectura, tanto en la escala de lo edificio cuanto en la escala da la ciudad. El artículo presenta en la primera parte una revisión de literatura trayendo los principales autores contribuyentes en este tópico. En la segunda parte el articulo presenta el conjunto de procedimientos constituyentes del método propiamente dicho. En una tercera parte el trabajo presenta un estudio de caso donde el método del observador es ejercitado.

Palabras clave: Caminada. Paseo arquitectónico. Calidad espacial. Funcionalidad. Legibilidad. 


\section{Introdução}

O método de descrição espacial delineado no que segue se vale da caminhada como ferramenta na avaliação da qualidade espacial dos lugares. ${ }^{3} \mathrm{Na}$ linha sugerida por Le Corbusier na sua promenade architecturelle, a caminhada, o dito passeio arquitetônico, propiciaria ao observador em movimento uma apreciação da qualidade espacial envolvida na situação em estudo. O objetivo do artigo é eminentemente metodológico e se detém a explorar esse modo particular de olhar, descrever e avaliar a qualidade espacial ou, se quisermos, a performance espacial em Arquitetura, seja na escala da edificação, seja na escala da cidade; um modo fundado no ponto de vista de um observador caminhante, na escala urbana, um pedestre, alguém que experimenta, de modo direto, a interface corpo-espaço. O método, em sua busca de avaliar a performance espacial dos lugares, descreve o(s) impacto(s) dos elementos que constituem uma determinada situação espacial sobre o corpo, o corpo físico, sensível aos elementos que o circundam, espaços e objetos.

Diferentemente de um observador qualquer, o observador aqui pautado atua orientado por informação cartográfica referente ao seu objeto de estudo. Denominaremos esse modo de olhar como o método do observador. Entende-se, neste contexto (esta é a nossa hipótese de trabalho), que a qualidade ou performance espacial de edificações e lugares em geral estaria essencialmente fundada em duas propriedades inerentes ao espaço, ambas vistas e sentidas pelo observador em movimento: a legibilidade e a funcionalidade. Da combinação desses dois fatores decorreria a aprazibilidade e, em consequência, a vitalidade desses mesmos lugares, denunciada ali pela presença maior ou menor de pessoas. O método do observador, delineado no que segue, apoia-se na observação sistematizada e continuada desse conjunto de características do espaço, seja ele público, seja privado.

\section{Antecedentes}

O uso desse modo peculiar de apreciar a Arquitetura não é recente. Trata-se, de fato, do modo mais direto e natural de desfrute e avaliação espacial utilizado pelo homem, desde os primórdios. No entanto sua utilização, de modo sistemático, como instrumento de crítica na Arquitetura e na Arte, de um modo geral, é algo que tem início apenas no final do século XIX com os historiadores da arte alemães. Entre esses, Auguste Schmarsow é reconhecido como fundador de um novo modo de apreciação da Arquitetura como arte espacial: "Ele enfatizou o movimento do observador, o físico e o imaginado, e o seu papel na projeção de sentimentos individuais sobre a forma espacial estática" (KÖHLER, 1998). Schmarsow propõe uma apreciação da Arquitetura com base naquilo que ele denomina como cerne espacial e sugere que o dito cerne estaria no movimento do observador, e que a essência espacial da Arquitetura só pode ser vivida se tivermos a capacidade de nos colocar nessa posição de centros e, a partir daí, intuir a lógica espacial da situação vivenciada, diz ele:
3. Esse procedimento vem sendo exercitado na disciplina de Estudos da Qualidade Espacial, oferecida pelo autor no Propar/UFRGS, Curso de Pós-Graduação em Arquitetura da Universidade Federal do Rio Grande do Sul. 
Tão logo tenhamos aprendido a perceber a nós mesmos como centros do espaço - um espaço cujas coordenadas se interceptam sobre nós - teremos achado o precioso cerne, o investimento inicial no qual toda a Arquitetura está baseada. Uma vez que a imaginação ativa captura esse germe e o desenvolve de acordo com as leis dos eixos direcionais - leis essas inerentes mesmo à mais incipiente ideia ou situação (SCHMARSOW, 1994, 285).

Central no enunciado de Schmarsow é o conceito de direcionalidade, associado ao corpo em movimento, a definir a atitude e percepção do observador que, nessa linha, entenderia, compreenderia a Arquitetura de um modo natural, com base na lei dos eixos direcionais. Schmarsow sugere que a direção mais importante em uma estrutura espacial seria a direção do livre movimento adiante e que a nossa visão, em virtude do posicionamento dos olhos, definiria uma, permanentemente mutante, dimensão de profundidade, o que naturalmente implica o reconhecimento da dimensão cinestésica do corpo ao mergulhar no espaço arquitetônico. Estaria aí o embrião do que, algumas décadas adiante, Le Corbusier denominará como passeio arquitetônico, a promenade architeturelle, procedimento, para ele, chave na descrição da qualidade espacial e performance em Arquitetura.

Esse modo de ver a Arquitetura tornar-se-á, na virada para o século XX, a base do pensamento arquitetônico das vanguardas, no que diz respeito à espacialidade. Le Corbusier aprofunda e especifica o movimento do observador, naquilo que os historiadores alemães haviam, 50 anos antes, denominado como vitalfuhlung que, numa tradução aproximada, corresponderia ao sentimento ou à sensação da essência espacial, diz ele:

O eixo é talvez a primeira manifestação humana; ele é o meio de toda a ação. A criança em seus primeiros passos busca mover-se ao longo de um eixo, o homem se debatendo em meio a tempestade traça para si próprio um eixo. O arranjo é a gradação de eixos, e assim também a gradação de objetivos, a classificação das intenções (LE CORBUSIER, 1931, p. 187).

Le Corbusier descreve nessa passagem o movimento do observador de um modo peculiar, utilizando-se da condição de axialidade como fundamento na ordenação do percurso. O passeio arquitetônico, qualquer que seja, seria na essência composto ou constituído por eixos, axialidades e quebras de axialidade ou, se quisermos, inflexões. Trata-se aqui de um detalhamento, uma especificação da lei dos eixos direcionais de Schmarsow. Na gradação dos eixos, está por definição implícito o conceito de integração e segregação espacial; o mais visível e o menos visível, o mais acessível e o menos acessível. Essas seriam, para Le Corbusier, as características de um passeio arquitetônico adequadamente espacializado, uma situação na qual a gradação dos eixos contribuiria com o efeito espacial, na realização da atividade. Através da gradação dos 
eixos, ele nos fornece o instrumental para a avaliação da qualidade espacial. De fato, o entendimento da Arquitetura a partir do passeio arquitetônico vem apenas a recuperar um modo ancestral de leitura do espaço.

Le Corbusier antecipa as diferentes descrições, e pontos de vista, inerentes ao método do observador. De um lado, está a experiência espacial que é, para ele, parte preponderante no entendimento do espaço. Do outro lado, está a descrição em planta, a referência planimétrica impreterível para que o observador mergulhe nos meandros da espacialidade: "A planta é um sumário, algo como um índice analítico, e de modo tão condensado que parece clara como um cristal. E, como figura geométrica, ela contém uma quantidade enorme de ideias e o impulso de uma intenção" (LE CORBUSIER, 1931, p. 179). Crucial nesse parágrafo é o entendimento profundo do papel da planta como um complexo banco de informações revelador de um ângulo, e de uma racionalidade, vindo da visão planimétrica do objeto e, por natureza, inacessíveis à experiência espacial.

Esse procedimento descritivo é utilizado por Le Corbusier em cartas a clientes (Vila Mayer, 1925), nas quais se vale de imagens de sequências espaciais para explicar o projeto. E aparece também na conhecida descrição da Casa Vetti, em Por uma Arquitetura, em que imagens em perspectiva e planta compõem uma descrição espacial articulada. Em ambos os casos, a relação entre a descrição em planta e o corpo em movimento é a demonstração do efeito espacial. No início da década de 1960, Gordon Cullen retomaria esse procedimento (com plantas e sequências de perspectivas descrevendo situações espaciais) no conceito de visão serial, tendo como ponto de vista aquele do observador em movimento, e que se desdobra continuamente em uma visão existente e uma visão emergente. A descrição espacial trazida por Cullen oferece a observação simultânea da planta mostrando a sequência de posicionamentos do observador em movimento, e a sequência de imagens correspondentes ao que é visualizado desde esses mesmos posicionamentos ou estações, se quisermos. O relato em planta e o relato da sequência espacial por meio de imagens, desde o ponto de vista do observador em movimento, complementam-se.

A percepção desse caráter estrutural por meio da visão do percurso é denominada por Lynch (2006) como a legibilidade dos lugares. Para ele, a legibilidade dos lugares dependeria de uma percepção de continuidade espacial. Diz ele: "A exigência fundamental é que o percurso em si, o leito pavimentado, sigam adiante; a continuidade de outras características tem menos importância" (LYNCH, 2006, p. 59). A noção estrutural de um leito pavimentado conformando uma rede espacial seria a mais percebida. Diz ele: "As vias, a rede de linhas habituais ou potenciais de deslocamento são o meio mais poderoso pelo qual o todo pode ser ordenado" (LYNCH, 2006, p. 106). A pesquisa de Lynch sugere igualmente a importância de uma hierarquia visual; segundo ele, "uma escolha sensória dos canais principais e sua unificação como elementos perceptivos contínuos." Esse seria, segundo Lynch, o esqueleto da imagem da cidade. Curiosamente, essa ambicionada "unificação dos espaços da cidade 
como elementos perceptivos contínuos" termina sendo pouco percebida nas descrições gráficas resultantes da pesquisa de Lynch. A ênfase nessa condição estrutural não impede que Lynch reconheça também o potencial de satisfação decorrente da presença de elementos-surpresa no andamento urbano. Há que considerar aí que a condição de surpresa seria, em qualquer caso, produto de uma alteração inusitada, inesperada, na legibilidade, ou seja, a linha de visão indicaria, nessa situação, algo diferente daquilo que iria de fato ocorrer; o que, para alguns, poderia constituir em um potencial de satisfação, enquanto que, para outros, poderia se constituir em um incômodo ou mesmo ser a causa de um contratempo ou até de um acidente. De qualquer modo, ainda que a pesquisa de Lynch aconteça predominantemente na escala da cidade, sua conceituação é absolutamente espacial e arquitetônica.

O trabalho de Herman Hertzberger (1972) quantifica, em planta, as gradações espaciais, a dita gradação dos eixos teorizada por Le Corbusier, e naturalmente descritas pelo deslocamento do observador no espaço arquitetônico:

Marcando as gradações de acessibilidade pública das diferentes áreas e partes da planta, uma variedade de mapas mostrando as diferenciações territoriais serão obtidos. Esses mapas mostrarão claramente que aspectos da acessibilidade existem (HERTZBERGER, 1972, p. 13).

Hertzberger mostra, por meio de diagramas, o que ele denomina como diferenciação territorial a qual se estabelece por meio das gradações de acessibilidade. Ele mostra como a estruturação espacial, em sua busca de adequação ao movimento do corpo, deve ser fundada em gradações de acessibilidade que ordenem espacialmente as atividades, aquilo que se conhece em Arquitetura como programa. Sugere ainda que o fundamento da distribuição espacial resida na consciência, por parte do observador, das diferentes demandas territoriais e modos de acessibilidade requeridos. Hertzberger amplia o entendimento dos conceitos de público e privado relacionando-os ao tema da acessibilidade:

Os conceitos de público e privado podem ser vistos e compreendidos em termos relativos como uma série de características espaciais que, diferenciando-se gradualmente, denotam acessibilidade, responsabilidade e a relação entre o domínio privado e o controle sobre situações espaciais específicas (HERTZBERGER, 1972, p. 17).

O método de Hertzberger confere um caráter estrutural às gradações da sequência espacial que seria crucial no modo como as situações são lidas ou entendidas pelas pessoas.

O papel de Hillier e Hanson (1984) na construção do método do observador ora delineado se refere essencialmente à qualificação da base cartográfica utilizada pelo observador em movimento, ou seja, o relato planimétrico e cartográfico dado em planta. Hillier propõe uma descrição sintética de situações espaciais baseada nas linhas de movimento sugeridas pelo arranjo espacial e decorrente do modo de agrupamento das edificações 
e espaço aberto. Essa descrição é conhecida como mapa axial (HILLIER, 1983). No mapa axial, a gradação dos eixos, descrita anteriormente por Le Corbusier, ganha uma descrição sistêmica. Cada uma das linhas de movimento tem uma identidade decorrente e relativizada ao todo; o conjunto de linhas de movimento que compõe uma determinada situação arquitetônica ou urbana. Esse conjunto de linhas de movimento constituiria uma espécie de DNA, a identidade espacial, dessa situação. O mapa axial detectaria essa alma ou essência espacial. Valho-me das palavras de Lynch (2006) para explicitar a descrição dessa ponte que une um diagrama e a realidade física dos lugares: "Um mundo físico aparentemente desordenado pode organizar-se mediante a invenção de um diagrama simbólico que explique as relações das características principais de uma maneira que estimule o desenvolvimento da imagem" (LYNCH, 2006, p. 107108). Nessa linha, o observador deslocar-se-ia, no método ora delineado, amparado por fotos de satélite, cartografia urbana e, dependendo do caso, por diagramas que relatam a condição de centralidade e, por conseguinte, a quantidade de integração e segregação espacial inerente aos espaços percorridos.

\section{A construção do método}

O procedimento ora delineado está fundado na conduta de um pedestre peculiar, um observador guiado por informação privilegiada, que se desloca pelos lugares; sensível às qualidades destes e com a intenção de descrevê-las. O modo descritivo assim delineado reúne, por um lado, as percepções desse observador que se desloca no espaço, registrada em imagens e texto; e, por outro, a informação privilegiada, o material cartográfico e diagramático que instruirá os deslocamentos desse observador, estruturando, assim, sua carga cultural. Nesse sentido, do uso recorrente de mapas a guiar uma caminhada, o procedimento herda características daquele usado pelos ditos situacionistas em suas explorações urbanas em busca dos assim denominados efeitos psicogeográficos emanados dos espaços da cidade (DEBORD, 1958), ainda que não guarde qualquer relação com passeios sem destino, as ditas derivas. De fato, quanto a esse procedimento, o uso de mapas ao longo de uma jornada, por definição, sem destino seria em si paradoxal.

Nessa linha, o material cartográfico de apoio ao método do observador ora delineado contém informações sobre as características espaciais dos lugares a serem explorados ao longo do percurso onde se procede esse reconhecimento da situação objeto de estudo. O método, baseado em uma base cartográfico-planimétrica, vale-se de diagramas na descrição da caminhada. Situações arquitetônicas e urbanísticas são descritas por meio do modo como ocorre seu contato, ótico e háptico, com o corpo em movimento. Essencial no procedimento é que o observador elabore o material a ser utilizado no passeio, material esse que ele estudará previamente, do mesmo modo como ocorre com aquele que estuda o mapa do tesouro antes de proceder à expedição em sua busca. 
Entende-se por diagramas desenhos sintéticos, linhas, traçados, delineamentos, esboços, distribuição de cores, que descrevam uma situação ou ideia. O diagrama é, em última análise, uma representação visual estruturada e simplificada de um determinado conceito, ideia ou situação. O método consta de categorias instrumentais pelas quais as situações, os espaços são descritos, e observações são registradas, e categorias analíticas pelas quais as situações são avaliadas.

A imagem a seguir (FIG. 1) mostra o conjunto de diagramas resultantes do método do observador quando utilizado na avaliação da qualidade espacial do Museu da FIC, em Porto Alegre. Esse caso é aqui utilizado como exemplo, por um lado, em virtude da variedade de escalas e temas que ele traz no que diz respeito à qualidade do espaço público, que vão desde a arquitetura urbana até a arquitetura de interiores, passando por diferentes gradações de acessibilidade. O procedimento se estrutura ao modo de uma ecografia arquitetônica que relata a espacialidade da situação, ou seja, relata o modo como ocorre a relação entre espaços e corpo(s). O relato nesse caso consta de oito situações que relatam o movimento do observador em sua aproximação ao edifício, no acesso e ao percorrer seu interior. Cada uma das situações é relatada por meio de um diagrama e da sequência de imagens correspondente formando um todo articulado.

Em qualquer caso, o centro da descrição é o texto, o relato do observador. Esse registro textual se vale da sequência de imagens para mostrar ao leitor aquilo que o texto está descrevendo. O diagrama é uma terceira descrição, uma descrição abstrata, que propicia ao leitor uma outra visão espacial, uma ligação (uma representação intelectual, diagramática) entre essas outras duas descrições, o texto e as imagens da dita visão serial.

\section{Categorias instrumentais}

Cada um dos diagramas mostrados acima apresenta, de modo sintético, as categorias instrumentais que constituem a base visível do procedimento, o registro gráfico da experiência do observador, que é justaposta à sequência de imagens produzidas por esse mesmo observador ao longo do seu caminho.

\section{A planta}

A primeira das categorias instrumentais é a planta. As descrições do objeto de estudo em planta são a referência de base na definição do(s) percurso(s) utilizado(s) no procedimento. Não se trata aqui de uma planta qualquer, mas de algo que denominaremos como planta mínima. Os diagramas acima mostram uma descrição em planta na qual o edifício e seu entorno imediato são reduzidos à condição diagramática de barreiras e passagens. A inserção do objeto de estudo em um entorno imediato objetiva que a análise tenha como ponto de partida essa condição sistêmica ou condição de rede inerente a toda e qualquer situação espacial. Entende-se, nesse contexto descritivo, paredes e 

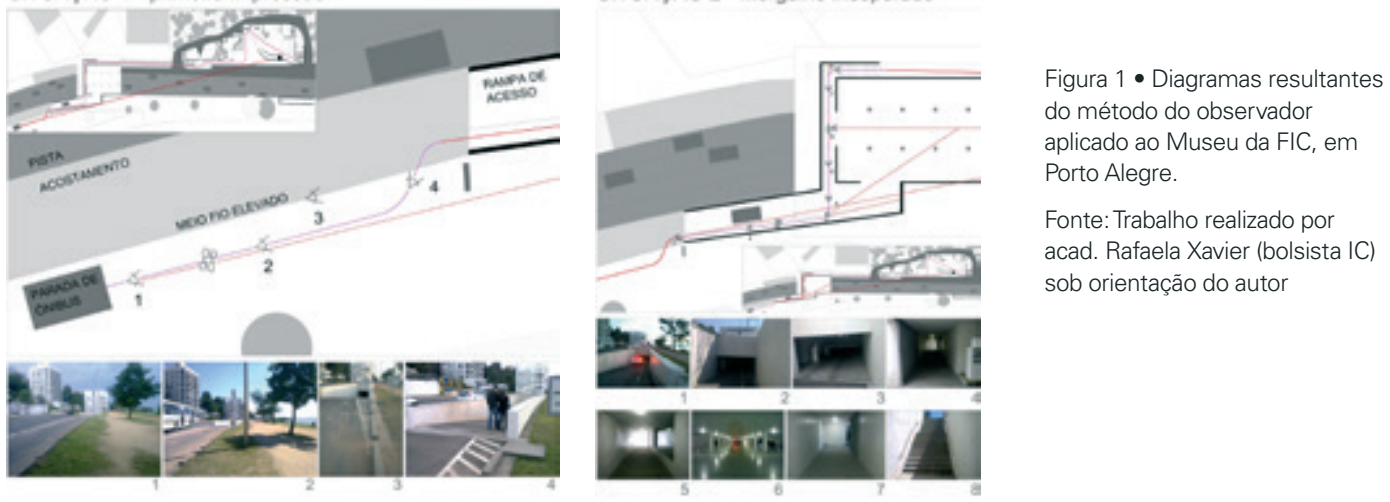

SITUACĂO 3 - percurso de aproximaçăo
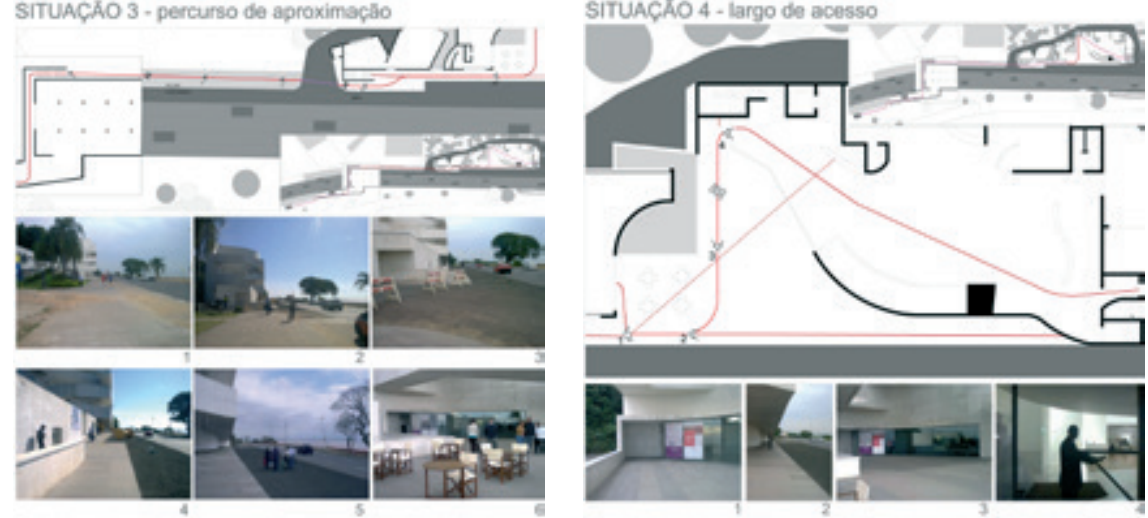

SITUAC,ĀO 5 - o grande átrio

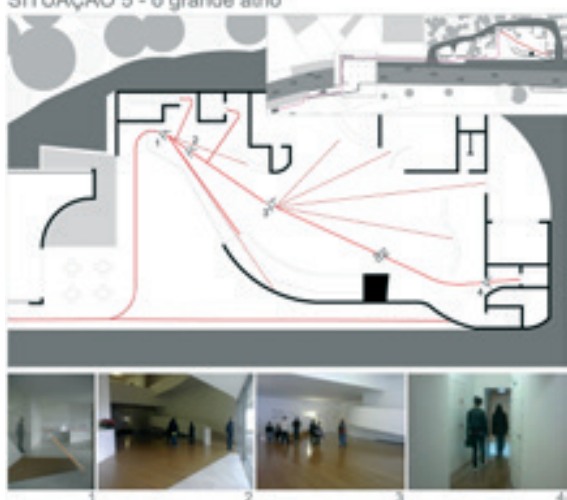

SITUAÇÃO 6 - o acesso às exposiçסes (elevador 2)
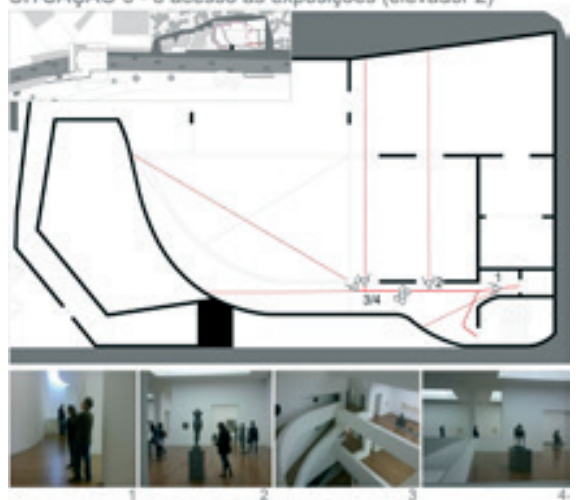

SITUAÇĀO 7 - as salas de exposiçầo
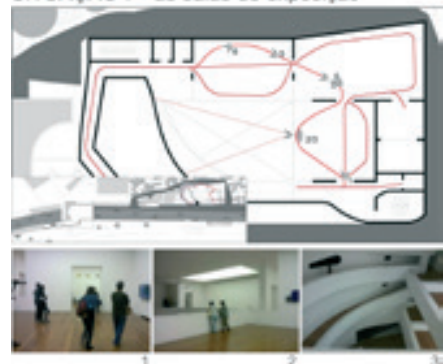

SITUACÁ 8 - as passarelas tubulares
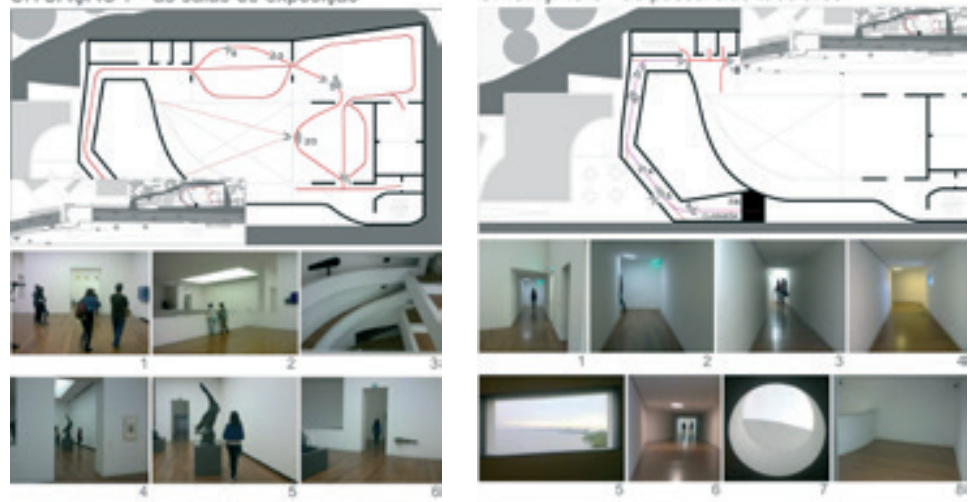

Cadernos de Arquitetura e Urbanismo, v.22, n.31, 2º sem. 2015 
mobiliário como barreiras, e os espaços vazios como passagens, o domínio do(s) corpo(s). Trata-se, a planta, de uma descrição essencialmente morfológica. Na escala urbana, o objeto de estudo é descrito como figura, ao modo do mapa Nolli de Roma (1735). O fundo, em branco, é o domínio do corpo e das linhas de movimento. A informação dada na planta mínima é complementada por informação vinda de um entorno ampliado, por meio de fotos de satélite, mostrando a situação em uma escala global. ${ }^{4}$

\section{O percurso}

Os diagramas mostram os percursos sugeridos pela planta do objeto de estudo. Para cada uma das situações há um percurso mais apropriado ao objetivo de desvendar a performance espacial daquela situação; a sequência espacial principal. O percurso, uma vez referenciado à planta mínima, é descrito por meio de diagramas de linhas de movimento. Esse diagrama descreverá, de modo literal, o movimento do observador, sua rota, por segmentos de reta e mudanças de direção, inflexões. Essa descrição do percurso como uma sequência de segmentos axiais propicia a identificação e a diferenciação de partes fundada na descrição das mais longas linhas de visada, e propiciará a avaliação das características de legibilidade dessas diferentes partes do percurso tanto em separado quanto em sua associação com as partes a ela adjacentes. Essa associação entre partes e todo, decorrente da descrição axial, propicia um entendimento sistêmico da Arquitetura; o objeto arquitetônico ou urbano descrito como um sistema de espaços. Daí decorre a identificação de uma hierarquia espacial. Essa hierarquia está descrita por Le Corbusier na dita gradação dos eixos (forma), que ele relaciona com a gradação das intenções (programa/função). Hertzberger (1972), como vimos acima, refere-se a essa mesma hierarquia em termos de gradações de acessibilidade, e Hillier et al. (1983) em termos de profundidade (depth), descrita na medida de integração espacial, esta fundada no diagrama de linhas axiais. Na descrição axial, cada parte do percurso é um espaço. E cada parte do percurso é também um lugar. A linha axial tem uma dimensão local, háptica, táctil, onde o corpo experimenta o espaço e, simultaneamente, uma dimensão global, ótica, decorrente de sua inserção em um todo maior.

\section{Delimitação espacial, convexidade e constituição}

A terceira categoria instrumental está no modo como o conceito de situação espacial utilizado no método do observador desagrega o objeto de estudo em termos das diferenciações espaciais verificadas ao longo do percurso, os diferentes lugares. Hillier generaliza o conceito de lugar em termos de espaços convexos, ou seja, convexidades. Toda e qualquer Arquitetura ou situação urbana poderia, nessa linha, ser descrita em termos do seu conjunto de espaços convexos (HILLIER et al., 1983). A condição de convexidade, com base em sua caracterização geométrica, é um modo objetivo de conceituar lugar;
4. No caso do exemplo utilizado, o material sobre o edifício do museu foi fornecido pela Fundação Iberê Camargo em formato digital e redesenhado, de modo a reter tão somente aqueles elementos gráficos necessários às análises. 


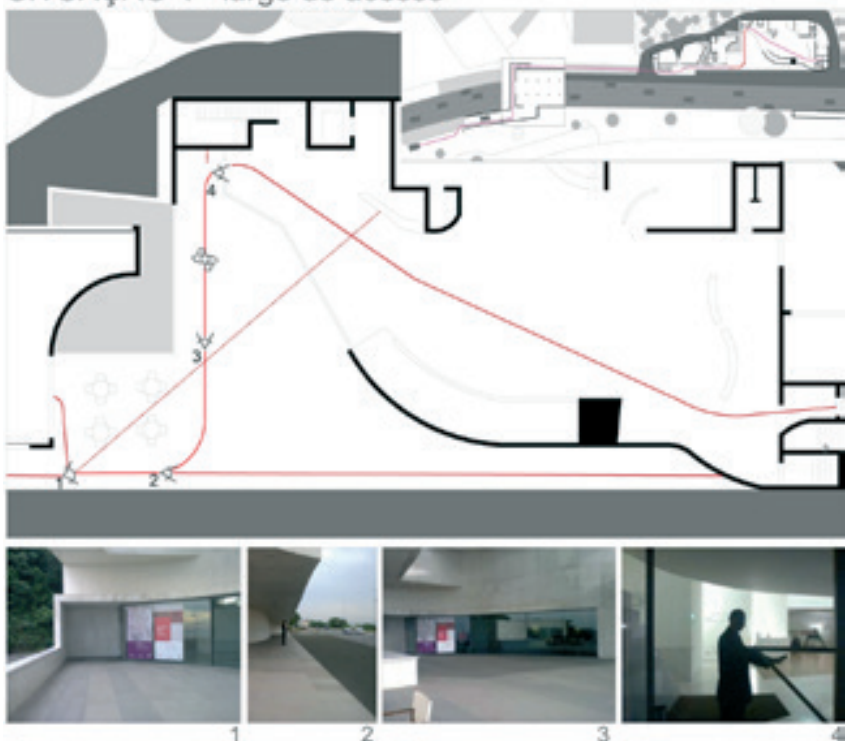

SITUAÇĀO 5 - o grande átrio

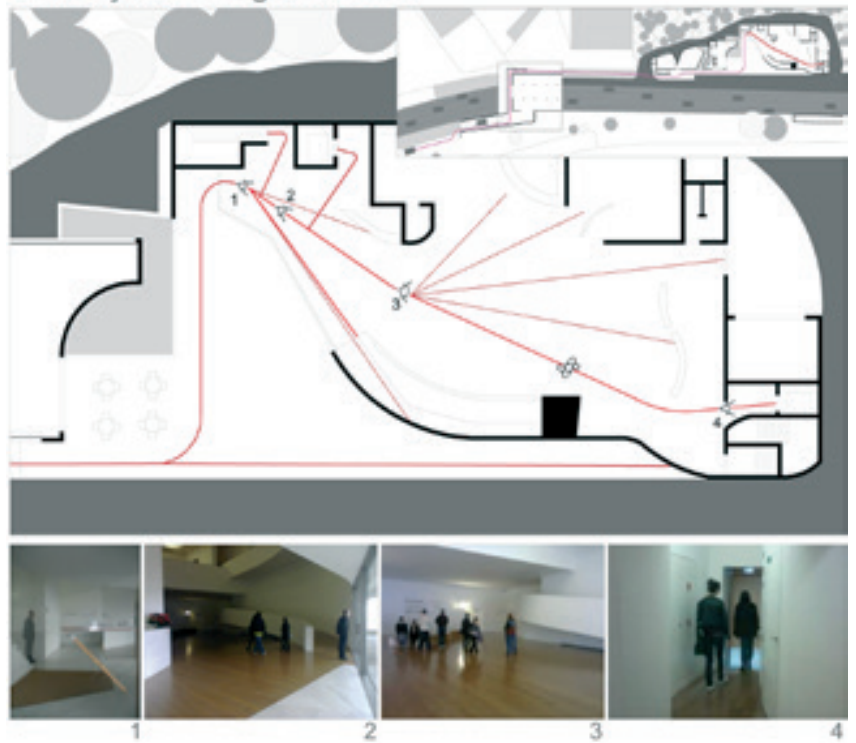

edificações e espaços públicos podem ser descritos como sequências de lugares. Trata-se, portanto, de descrever o objeto de estudo em termos da sua condição de abrigo ou, se quisermos, do seu grau de enclausuramento. O conceito implica no entendimento da Arquitetura em sua dimensão uterina. Na escala da cidade, a rua tradicional, espaço arquitetônico alongado margeado por edificações alinhadas em ambos os lados, seria a epítome do acolhimento espacial, síntese da noção albertiana de cidade como casa, a casa maior.

No procedimento mostrado no conjunto de diagramas, os lugares, além da caracterização geométrico-planimétrica elaborada acima, são igualmente caracterizados pelo modo como são constituídos, ou seja, pelo modo como se materializa o envoltório material desse espaço, suas laterais, paredes e

\section{Figura $2 \bullet$ Situações 4 e 5}

Fonte: Trabalho realizado por acad. Rafaela Xavier (bolsista IC) sob orientação do auto

Cadernos de Arquitetura e Urbanismo, v.22, n.31, 2 sem. 2015 
outros limites virtuais, tais como a paisagem, que margeiam o percurso. E trata-se também do fechamento superior, que pode ser o céu, e também do chão, o piso, sobre o qual o espaço acontece. Essa característica, no caso ora tomado como exemplo, é descrita na sequência de imagens. Trata-se, portanto, de descrever a totalidade do envoltório material do percurso ou, se quisermos, o modo como o percurso é constituído. Uma constituição positiva é, em geral, dada pela presença de portas e janelas voltadas para o percurso; são os olhos da rua (JACOBS, 1960). Paredes cegas são, em geral, uma contribuição negativa ao percurso. Paredes cegas podem, no entanto, ocasionalmente, carregar forte conteúdo simbólico/valor icônico. A constituição dos espaços é representada, no procedimento analítico ora delineado, pela(s) fachada(s) esquemática(s) e, ou, por corte(s) esquemático(s) em paralelo à totalidade do percurso exemplificar. A condição ou grau de convexidade dos espaços que margeiam o percurso está, nesse procedimento, descrita nessa categoria da constituição do espaço.

\section{Visão serial}

Trata-se aqui do registro fotográfico do modo como o percurso é visto pelo observador em movimento, mostrando a sequência de imagens do percurso obtida ao longo do passeio arquitetônico. Trata-se, portanto, de fotografar o percurso, cada uma das partes do percurso, ou seja, cada uma das linhas de visada. A totalidade do percurso será, portanto, descrita por meio da sequência de imagens, mostrando o passeio arquitetônico. Esse procedimento está descrito em Cullen (1961) pelos conceitos de visão existente e visão emergente. A posição ou o ponto de vista da câmera estará localizado nos pontos de conexão entre diferentes linhas axiais, ou seja, nos links que conectam a sequência de linhas. O link fornece a posição da câmera ao descrever as mais longas linhas de visada. Cada linha, cada parte do percurso tem a sua imagem, na qual a própria imagem da linha poderá se materializar, dependendo da conveniência exemplificar.

\section{Categorias de avaliação}

Tendo como base os elementos dados pelas descrições gráficas e imagens, as categorias de avaliação constituem a essência do procedimento, a análise propriamente dita, conforme descrevem aquelas características assumidas como determinantes na qualidade ou performance espacial do objeto de estudo.

\section{Legibilidade, a clareza espacial e o espaço confuso}

A primeira dentre as categorias de avaliação é a legibilidade da situação, condição que repousa na facilidade ou dificuldade de leitura do percurso em estudo, ou ainda, se quisermos, pelo modo como o observador em movimento compreende ou percebe a continuidade do percurso, condição-chave na legibilidade (LYNCH, 2006). Nos diagramas mostrados acima, 
as linhas de visada indicam a sequência do percurso e seu modo de acesso, sua acessibilidade. O conceito está fundado na dimensão ótica da Arquitetura, a compreensão obtida por meio do olho, da linha de visada do observador em movimento, do entendimento, maior ou menor, do andamento espacial do objeto de estudo, edifício ou situação urbana. O conceito de inteligibilidade operacionaliza, instrumentaliza o conceito de legibilidade. A inteligibilidade, nessa linha, estaria na percepção de um entorno ampliado com base em elementos espaciais sugeridos pela percepção local (HILLIER et al., 1983). A descrição do percurso por meio do diagrama de linhas (de movimento e de visada) somada à visão da sequência de imagens, é a base de registro da condição de legibilidade. A sequência fotográfica documenta aquilo que o registro em texto descreve.

\section{Funcionalidade, o cômodo e o incômodo}

A segunda categoria de avaliação é a condição de funcionalidade, que se refere ao modo como as situações espaciais afetam a comodidade das pessoas. Funcionalidade se refere ao cômodo e ao incômodo. Ao contrário da legibilidade, que é fundada essencialmente na dimensão ótica da percepção espacial, a funcionalidade estaria fundada essencialmente na dimensão háptica ou táctil da percepção espacial, ou seja, em fatores que afetam o corpo além da dimensão ótica; esforços, desconfortos térmicos, desconfortos dimensionais, etc. Inúmeros podem ser esses fatores. A condição de altimetria ou topografia parece ser um fator crucial na funcionalidade dos lugares. Nos diagramas acima, situações dotadas de declividades acentuadas, ladeiras, rampas e escadas são mostradas como problemáticas, cores são utilizadas apontando a condição problemática, tanto pelo esforço maior exigido para o deslocamento quanto pela perda da visibilidade daquilo que ocorrerá após o topo da ladeira. Nesse sentido, à funcionalidade problemática estará associada uma perda de integração espacial, mesmo que o percurso siga em linha reta.

Situações espaciais desse tipo são em geral hostis às pessoas, ao caminhante. Desde o ponto de vista da qualidade espacial, a cidade plana seria a cidade ideal, assim como o foi para $\mathrm{Hi}-$ pódamo de Mileto. Em edificações, a presença de escadas e rampas produziria, em qualquer caso, situações de utilização incômoda. Nessa linha, o fascínio da Arquitetura modernista por rampas iria precisamente na mão contrária da qualidade espacial, do mesmo modo que o gosto contemporâneo pelos assim denominados lofts, apartamentos duplex dotados de escada interna.

As características da calçada de uma determinada situação urbana seria um fator crucial em sua funcionalidade, em se tratando do conceito de qualidade espacial ora em tela, onde o pedestre é protagonista. A funcionalidade da calçada se expressa de diferentes modos, ou seja, em sua dimensão, isto é, sua largura, na qualidade do seu piso, no modo como é protegida ou não por marquises, galerias ou arcadas e, finalmente, na arborização que ela oferece. Ruas com calçadas acanhadas dificultam a utilização do espaço. Calçadas amplas e arboriza- 
das são, em geral, lugares esplendidos de passagem e estar. Calçadas dotadas de marquises, galerias, arcadas são, em geral, locais dotados de funcionalidade plena, intensa vitalidade e, nessa linha, um alto grau de qualidade espacial. Nesse quesito, o museu da FIC, descrito nos diagramas acima, revela-se um edifício, de fato, problemático.

A calçada é naturalmente afetada pelas características/qualidades das edificações que a margeiam, ou seja, por aquilo que denominamos acima como a constituição do espaço. E é nesse quesito que as ditas urbanizações novas são mais problemáticas. O que ocorre em geral com as calçadas em um urbanismo no qual o espaço público é relegado à condição de espaço viário? Temos aí calçadas sem delimitação espacial, sem portas, sem janelas ou qualquer outro motivo que estimule que por ali se caminhe. O que se vê hoje nas urbanizações novas são calçadas delimitadas por extensos muros cegos. Nos shopping-centers, as calçadas se diluem em meio a megaestacionamentos. Nas adjacências das autopistas urbanas, a calçada é o que mais sofre, especialmente pela descontinuidade, agravando a condição de hostilidade desse tipo de espaço público povoado de carros e deserto de pedestres. As lições de um passado urbanístico épico, fundado na arquitetura da avenida e do bulevar, ao que parece, caíram no esquecimento.

\section{Vitalidade}

Trata-se aqui da descrição da ocupação dos espaços pelas pessoas. Os diagramas mostram o método do observador capturando e registrando a presença de pessoas tanto na sequência de imagens dada na visão serial de cada situação espacial quanto nas plantas povoadas por humanoides. A presença de pessoas sugere que aquele espaço, aquele lugar, tenha vitalidade. Em qualquer caso, a vitalidade pode ser descrita em termos do grau de vitalidade. Na escala do espaço público, a vitalidade é simultaneamente local e global, arquitetônica e urbanística, dependente de uma adequada sobreposição das duas escalas. A vitalidade será expressa em planta por meio da presença maior ou menor de calungas-humanoides nos espaços descritos, ao longo dos percursos. O humanoide será descrito em seu comportamento espacial: andando, parado ou sentado, porém, em qualquer caso, sempre relacionado ao percurso. Trata-se, portanto, de observar e contar pessoas, classificando-as segundo o seu comportamento espacial. Os diagramas de percursos deverão levar em conta os diferentes atores intervenientes em uma determinada situação. Diferentes atores terão suas rotas identificadas com diferentes cores. Esse procedimento implicará na realização de observações do padrão de movimento naquela situação. A presença de pessoas, ou de mais pessoas, em um determinado lugar pode ser um indicio de qualidade espacial. Não seria, no entanto, um determinante. Em qualquer caso, a qualidade espacial seria enfatizada pela vitalidade, que mostra os espaços literalmente funcionando. Em qualquer caso, não parece ser adequado que o conceito de vitalidade seja aplicado à descrição do movimento de pessoas em interiores de edifícios; quando, de fato, está se tratando de movimento de pessoas ou, dependendo do caso, de movimento de público. 


\section{Aplicação do método do observador e das linhas}

O relato dado no que segue é uma demonstração do método do observador, mostrando a dita ecografia espacial, descrição que integra diagrama, sequência de imagens e o relatório em texto, descrevendo, como exemplo, duas situações estudadas no trabalho realizado no museu da Fundação Iberê Camargo (FIC), em Porto Alegre. ${ }^{5}$ Diagrama e imagens mostram, de modo articulado, o observador se deslocando, incorporando o papel do visitante que chega ao museu de ônibus, utilizando o transporte público. Entende-se como situação um espaço ou conjunto de espaços, localizados ao longo ou adjacentes ao percurso do observador, e que compartilham de um mesmo campo visual. Cada situação é descrita por uma sequência de imagens tomadas cada uma delas de um ponto ao qual denominaremos de estação. Cada estação está identificada no diagrama com o símbolo do olho, ou câmera, e sua numeração, à qual está associada a imagem correspondente.

São utilizadas, no que segue como estudo de caso, as descrições de duas situações analisadas no passeio realizado ao museu da FIC. A primeira delas denominamos como primeira impressão. A imagem tomada da estação 1 mostra a visão do observador ao descer do ônibus, desde o acostamento da autopista, observando o museu a uma distância de algo como 200 metros. Os diagramas mostram essa longa linha de visada; o diagrama menor mostra a linha em sua totalidade. ${ }^{6}$

O conjunto de imagens mostra que o isolamento do lugar é povoado de automóveis em velocidade. Ainda que o observador faça, desde onde está, um esforço para colocar o edifício do museu em foco (pela curiosidade/ansiedade do primeiro contato), seu campo ótico é, em sua maior parte, apropriado pela presença forte de um edifício residencial, igualmente branco, de maior porte comparado ao museu, em estilo neomediterrâneo, pastiche típico da década de 1970. O museu, para o visitante, repousa ao fundo, meio encoberto pelo posteamento, como a última edificação nessa sequência de objetos surgida para ele de modo inusitado (estação 2). E a ponta do Melo, que ele havia antecipado como um lugar isolado, aparece agora, em realidade, como um local povoado de tráfego viário e arquitetura medíocre que, de modo surpreendente, emolduram a espetacular arquitetura do museu. ${ }^{7}$ Diagrama e imagens mostram agora o visitante deixando para trás a parada e ônibus e se deslocando por uma calçada desprovida de pavimento e margeada por um meio-fio elevado que funciona como barreira a ser transposta. Ele percebe à sua frente uma placa indicando acesso para pedestres, coincidente com o acesso ao estacionamento. Para acessar a rampa, ele deve literalmente pular sobre o meio-fio que se eleva da calçada, constituindo mais um obstáculo que um facilitador. O diagrama acusa o observador, pulando o meio-fio elevado; e a linha de percurso sofre alteração de cor (estação 3). E ele então se dá conta de que o caminho a ser seguido daí em diante é bem diferente daquele sugerido pela longa linha de visada inicialmente observada. Uma rampa, paralela à rodovia, surge
5. Trabalho realizado em conjunto com os alunos das turmas de 2013/2 e 2014/2 da disciplina de Estudos da Qualidade Espacial, oferecida pelo autor no Propar/ UFRGS, Curso de Pós-Graduação em Arquitetura da Universidade Federal do Rio Grande do Sul.

6. Os diagramas constantes deste trabalho foram elaborados por Rafaela Xavier (bolsista PIBIC/CNPq), tendo em conta e sintetizando o material resultante dos trabalhos realizados pelas turmas de mestrado. 
então à sua frente, sugerindo um mergulho inesperado como opção única de encaminhamento na direção do museu (estação 4). A outra possibilidade de acesso ao museu seria atravessar a autopista, o que, naquele ponto, pode ser considerado como uma operação de alto risco, para qualquer pessoa normal, e uma missão impossível para pessoas com qualquer limitação, especialmente de idade.
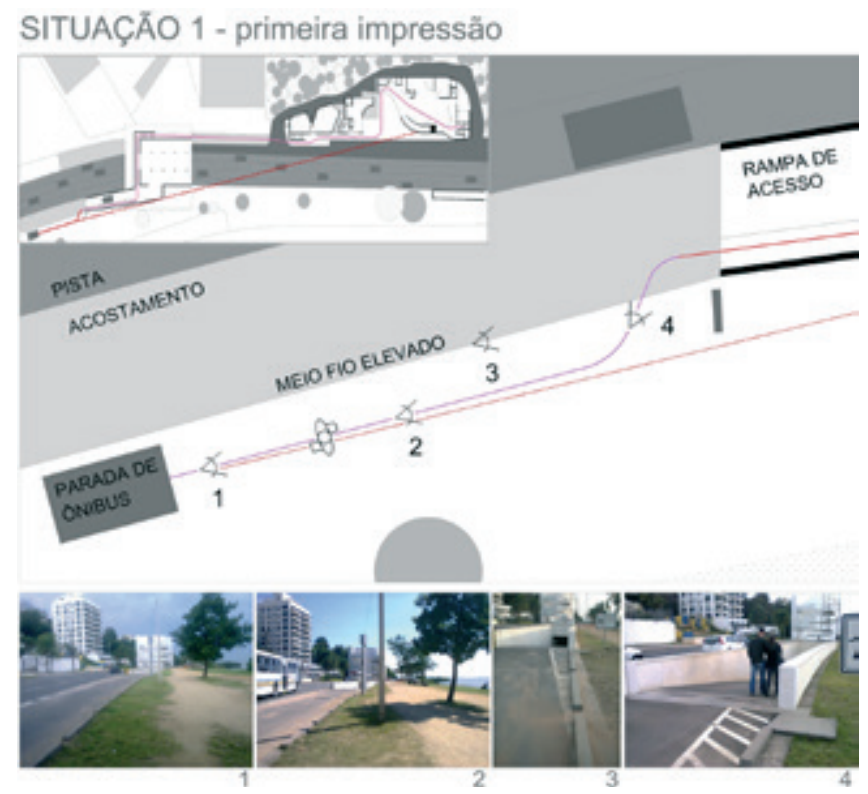

$\mathrm{Na}$ imagem a seguir, os registros correspondentes à situação 2 do procedimento (situação que viemos a denominar como mergulho inesperado) mostram o observador descendo pela rampa, vendo o museu desaparecer do seu campo visual (estação 1). Ele é acompanhado por um carro que, casualmente, também chega. Como visitante não motorizado, o observador se sente desconfortável com a situação esquisita em que é colocado. O diagrama acusa o vermelho padrão do percurso que se torna roxo novamente. No final do declive, o observador tem à sua frente uma parede cega (estação 2).

O diagrama mostra que à frente, em diagonal, à esquerda, descortina-se o interior do estacionamento e, à esquerda, mais escondido, está o túnel que se oferece a ele, assim como ao público em geral que chega por ônibus, para a travessia viária. A leitura da situação é problemática. O diagrama, juntamente com a imagem 3, descreve o descompasso entre linha de movimento e as linhas de visada que se apresentam ao observador como opções de percurso. Ele opta naturalmente pelo percurso que sugere a travessia de modo mais direto e, seguindo seu caminho, depara-se com uma inconveniente sobreposição e cruzamento das circulações de pedestres e veículos. Ele percebe aí que a aproximação ao museu se torna progressivamente esdrúxula, ao experimentar no subsolo uma mudança dramática nas condições, do exterior para o interior, do claro para o escuro, da visada inicialmente focada na forma espetacular do museu que o aguardava até o inesperado mergulho nesse espaço cavernoso onde agora ele se encontra. A
7. A ponta do Melo é uma das penínsulas que margeiam o rio Guaíba, que banha a cidade de Porto Alegre, onde se localiza o museu da FIC.

Figura 3 • Situação 1

Fonte: Trabalho realizado por acad. Rafaela Xavier (bolsista IC) sob orientação do autor 


\section{SITUAÇÃO 2 - mergulho inesperado}

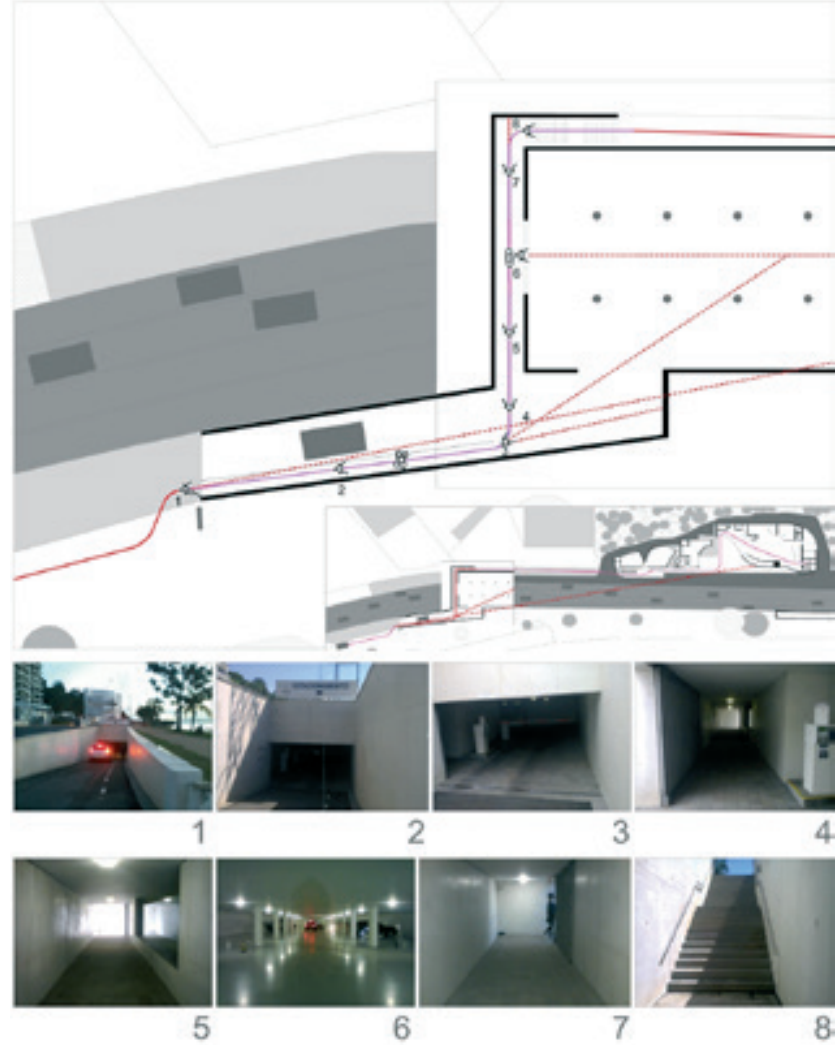

visualização da situação nesse momento sugere confinamento (imagem 4). Curiosamente, em meio a esse corredor subterrâneo, o observador vê a sensibilidade do arquiteto revelar-se. O diagrama mostra: em uma das paredes laterais desse espaço enclausurado do túnel, surge, para o observador, uma grande abertura (com algo como seis metros ao longo por um metro e meio) vedada com vidro fixo, através da qual se vê o estacionamento (imagem 5). A visão é surpreendente (imagem 6). O espaço do estacionamento é organizado por uma colunata de espaçamento e proporções precisas a sustentar a laje da autopista. Ainda que seja apenas um estacionamento, o observador percebe que esse espaço reivindica, por conta própria, independentemente do museu ao qual serve, o status de obra de arte, evidenciado no ostensivo supérfluo que carrega, no brilho asséptico dos revestimentos que espelham a rigorosa axialidade perspectivada na disposição das luminárias. Curiosamente, diante dessa inesperada visão, a sensação de desconforto parece ser atenuada, especialmente tendo em conta a apreciação mais intelectualizada da Arquitetura inerente ao observador incorporado. Ainda na passagem subterrânea, percebemos um clarão no fundo do corredor que nos guiará de volta ao andar de cima, o espaço aberto (imagem 7). Tomamos a escadaria (imagem 8).
Figura 4 • Situação 2

Fonte: Trabalho realizado por acad. Rafaela Xavier (bolsista IC) sob orientação do autor 


\section{Epílogo}

Oportuno enfatizar, em conclusão, que o método de avaliação de desempenho espacial ora apresentado está fundado na descrição da qualidade espacial, isto é, no modo como o espaço acolhe o observador. Entende-se, nesse contexto teórico, a qualidade espacial como essencialmente decorrente de dois aspectos de uma determinada situação; a sua legibilidade e a sua comodidade. O conceito de legibilidade descreve o modo como a situação é compreendida, ou lida se quisermos, pelo observador. Essa leitura é dada pelo modo como informações de caráter local e global se complementam, fornecendo ao visitante orientação ao longo do seu percurso. A qualidade espacial, nesse quesito, decorreria da inteligibilidade da situação, uma característica detectada pelo olhar estendido, pela linha de visada, pelo foco, pelo ótico. A qualidade espacial implica, desde esse ponto de vista, que a situação tenha um andamento inteligível. O segundo aspecto da qualidade espacial prospectado pelo método do observador estaria na dimensão da funcionalidade ou comodidade e é algo mais localizado, e que se refere ao entorno imediato do percurso, e sua relação com o corpo. A comodidade vem, portanto, do modo como essas situações são apreciadas, percebidas, sentidas, pela visão periférica e pelos demais sentidos, um conjunto de percepções que constitui o háptico.

Essas duas dimensões (a legibilidade, vinda do ótico; e a comodidade, vinda do háptico) estiveram permanentemente sobrepostas na construção da percepção de qualidade espacial vivida pelo observador ao longo do percurso acima relatado. Daí parece resultar uma descrição pautada no senso comum, assemeIhada àquela percebida por uma pessoa qualquer caminhando, olhando e registrando o modo como o espaço por ela percorrido é melhor ou menos entendido, a dita legibilidade, e o modo como esse mesmo espaço é sentido, a dita funcionalidade ou comodidade, condições essas que ocorrem simultaneamente, ao longo de um percurso, e assim são relatadas por meio de imagens, diagramas e texto. De fato, a descrição do percurso via diagrama ocorre através ou por meio de descrições da legibilidade e da comodidade. Crucial aí é a participação da linguagem diagramática mostrando o modo como o espaço é constituído e o que objetivamente o torna mais ou menos legível, e também mais ou menos funcional ou cômodo/incômodo. Na observação dos diagramas, legibilidade e funcionalidade se reportam naturalmente à constituição do espaço, às paredes, ao envoltório espacial; descrições que não podem ser separadas.

Essencial também no procedimento é a elaboração oferecida ao conceito de situação que mostra uma descrição estruturada onde cada etapa do percurso tem seu relato em texto e, ao alcance do olho do leitor, o diagrama e a sequência fotográfica correspondente. Os diagramas adquirem sentido quando apoiados pelo texto e pelas imagens correspondentes, e vice-versa; um modo descritivo que se vale da simultaneidade destas três mídias descritivas (texto, diagrama e imagens) descrevendo um mesmo fenômeno físico-espacial. Nesse modo descritivo, as descrições de legibilidade e funcionalidade não são categorias autônomas, esse todo descritivo acontece simultaneamente, e 
o diagrama é a síntese do conjunto. As sequências de imagens/ fotos necessariamente correspondem àquilo que, de fato, é visto pelo observador em movimento. Essa é a pesquisa de campo. E é por isso que o percurso é decomposto em axialidades, as mais longas linhas de visada. Entende-se que essa condição estaria na base do conceito de legibilidade.

Destaca-se, finalmente em conclusão, como essencial neste texto a mensagem vinda dos ensinamentos e procedimentos aqui relatados, que tem origem na palavra de grandes mestres da cultura arquitetônica, mensagem essa que, espera-se, repercuta especialmente nos estudantes que vierem a tomar contato com este trabalho, fazendo despertar entusiasmo pela Arquitetura ao reafirmar o papel do desfrute e da avaliação espacial com base na caminhada como procedimento de ensino e pesquisa dentro da disciplina. Relembrando Zevi (1996), há sempre um novo mundo a ser desvendado a partir da submissão dos espaços à prova da passagem do corpo; do scanning do corpo através do espaço. O método do observador, em sua ambição de descrever a qualidade espacial dos lugares, parece ser um norte seguro onde ancorar o entendimento daquilo que seria uma arquitetura adequada às pessoas e ao nosso tempo.

\section{Referências}

CULLEN, G. Townscape. London: Architectural Press, 1961.

DEBORD, G. A Sociedade do Espetáculo, São Paulo: Contraponto, 1973

HERTZBERGER, H. Lessons for students of Architecture. Rotterdam: Uitgeverij 010 Publishers, 1972.

HILLIER, B. et al. Space syntax: a different urban perspective. Architecture Journal, London, n. 4, p. 47-63, 1983.

HILLIER, B.; HANSON, J. The social logic of space. Cambridge: Cambridge University Press, 1984.

JACOBS, J. The death and life of great american cities, Jonathan Cape, London, 1960.

KÖHLER, Bettina. Architecture history as the history of spatial experience. Daidalos, Berlin, n. 67, p. 36-43, 1998.

LE CORBUSIER. Towards a new Architecture. London: J. Rodker, 1931.

LYNCH, K. A imagem da cidade. São Paulo: Martins Fontes, 2006.

SCHMARSOW, A. The essence of architectural creation. In: Mallgrave, Harry Francis; IKONOMOU, Eleftherios (eds.). Empathy, form, and space, problems in German aesthetics: 1873-1893. Santa Monica: The Getty Center Publication Programme, 1994, p. 285-322.

ZEVI, B. Saber ver a Arquitetura. São Paulo: Martins Fontes, 1996. 
Cadernos de Arquitetura e Ubanismono, v.22, n.31, 2" sem. 2015 